\title{
Boron Isotope Fractionation in Bell Pepper
}

\author{
Sonja Geilert ${ }^{1,2}$, Jochen Vogl ${ }^{1 *}$, Martin Rosner ${ }^{3}$, Susanne Voerkelius ${ }^{4}$ and Thomas Eichert ${ }^{5}$ \\ ${ }^{1}$ Bundesanstalt für Materialforschung und-prüfung (BAM), Richard-Willstätter-Str.11, Berlin, Germany \\ ${ }^{2}$ GEOMAR Helmholtz Centre for Ocean Research Kiel, Wischhofstr. 1-3, Kiel, Germany \\ ${ }^{3}$ IsoAnalysis UG, Gustav-Müller-Str.38, Berlin, Germany \\ ${ }^{4}$ Hydroisotop $\mathrm{GmbH}$, Woelkestr.9, Schweitenkirchen, Germany \\ ${ }^{5}$ University of Bonn, Karlrobert-Kreiten-Str.13, Bonn, Germany
}

\begin{abstract}
Various plant compartments of a single bell pepper plant were studied to verify the variability of boron isotope composition in plants and to identify possible intra-plant isotope fractionation. Boron mass fractions varied from $9.8 \mathrm{mg} /$ $\mathrm{kg}$ in the fruits to $70.0 \mathrm{mg} / \mathrm{kg}$ in the leaves. Boron $(\mathrm{B})$ isotope ratios reported as $\delta^{11} \mathrm{~B}$ ranged from $-11.0 \%$ to $+16.0 \%$ o $(U \leq 1.9 \%, k=2)$ and showed a distinct trend to heavier $\delta^{11} \mathrm{~B}$ values the higher the plant compartments were located in the plant. A fractionation of $\Delta^{11} B_{\text {leaf-roots }}=27 \%$ existed in the studied bell pepper plant, which represents about $1 / 3$ of the overall natural boron isotope variation (ca. $80 \%$ ). Two simultaneous operating processes are a possible explanation for the observed systematic intra-plant $\delta^{11} \mathrm{~B}$ variation: 1) $\mathrm{B}$ is fixed in cell walls in its tetrahedral form (borate), which preferentially incorporates the light $B$ isotope and the remaining xylem sap gets enriched in the heavy $B$ isotope and 2) certain transporter preferentially transport the trigonal ${ }^{11} \mathrm{~B}$-enriched boric acid molecule and thereby the heavy ${ }^{11} \mathrm{~B}$ towards young plant compartments which were situated distal of the roots and typically high in the plant. Consequently, an enrichment of the heavy ${ }^{11} \mathrm{~B}$ isotope in the upper young plant parts located at the top of the plant could explain the observed isotope systematic. The identification and understanding of the processes generating systematic intra-plant $\delta^{11} \mathrm{~B}$ variations will potentially enable the use of $\mathrm{B}$ isotope for plant metabolism studies.
\end{abstract}

Keywords: Boron isotopes, Bell pepper, Boron transport, Boron isotope fractionation, Intra-plant isotope variability

\section{Introduction}

Stable isotope systems of major nutrients like oxygen or carbon have been successfully used to trace the provenance of plants and food products [1]. The boron (B) isotope system is of great interest in plants because B was found to be an essential micronutrient in plants occurring predominantly in the cell walls and acts as a strengthening component [2].

Boron has two stable isotopes, ${ }^{11} \mathrm{~B}(\sim 80 \%$ abundance $)$ and ${ }^{10} \mathrm{~B}(\sim 20 \%$ abundance) and its isotope amount ratio $n\left({ }^{11} \mathrm{~B}\right) / n\left({ }^{10} \mathrm{~B}\right)$ is reported as delta $(\delta)$-values (eqn. 1), referring to the Standard Reference Material $\left(\mathrm{SRM}^{\circ}\right) 951$ from the National Institute for Standards and Technology (NIST; Gaithersburg, USA). In aqueous solutions, B exists as uncharged trigonal boric acid $\mathrm{B}(\mathrm{OH})_{3}$ in acidic media or as tetrahedral borate ion $\mathrm{B}(\mathrm{OH})_{4}$ in alkaline media. The lower vibrational energy of the trigonal coordinated boric acid species causes a preferential incorporation of the heavier B isotope compared to the tetrahedral species [e.g. 3] leading to boron isotope fractionation in nature.

$$
\delta^{11} \mathrm{~B}=\delta^{11 / 10} \mathrm{~B}_{\text {NIST SRM } 951}=\left(\frac{R\left({ }^{11} \mathrm{~B} /{ }^{10} \mathrm{~B}\right)_{\text {sample }}}{R\left({ }^{11} \mathrm{~B} /{ }^{10} \mathrm{~B}\right)_{\text {NIST SRM951 }}}\right)-1
$$

To date, only few studies exist regarding B isotope compositions of plants. Published $\delta^{11} \mathrm{~B}$ values in crop plants and fruits range from about $-12 \%$ o to $+40 \%$ o [4-6] covering more than half of the natural $\mathrm{B}$ isotope variability. It was already suggested that depending on the involvement of natural and/or anthropogenic boron sources site specific $\delta^{11} \mathrm{~B}$ signatures occur in plants and food products [7]. However, provenance studies using boron isotopes as a tracer might be hampered by a potential isotope fractionation at the plant-soil interface and/or in the plant itself.

To date, no systematic study exists looking at natural intra-plant $B$ isotope fractionation, which might be caused by transport mechanisms or compartmentalization. Ref. [8] presented B isotope data of wheat, corn and broccoli growing experiments using artificial ${ }^{10} \mathrm{~B}$-rich nutrient solution and observed a preferential uptake of the heavy ${ }^{11} \mathrm{~B}$ isotope for wheat and corn and variable B isotope fractionations for broccoli.
The isotope signatures were interpreted as being potentially caused by varying adsorption mechanisms at the root plasmalemma or during B transport. However, the determined isotopic differences between the nutrition solution and the plant as well as the intraplant isotope variability seems to be unrealistically high and might not be caused by isotope fractionation induced solely by the plants. Contamination during sample preparation or a high procedure blank might additionally add to the extreme isotopic differences observed by ref. [8].

Here we present a full validation for $\delta^{11} \mathrm{~B}$ measurements applying multi-collector (MC) inductively coupled plasma mass spectrometry (ICPMS) including a new approach to calculate realistic uncertainties for $\delta$-values by standard bracketing. The $\delta^{11} \mathrm{~B}$ method was applied to study the boron isotope systematics in different plant compartments of one single bell pepper plant.

Bell pepper was chosen as a study object because B isotope compositions of bell pepper fruits have been investigated before for provenance studies and systematic variations have been identified [7].

Potential fractionation mechanisms will be discussed and an approach to explain the observed $\delta^{11} \mathrm{~B}$ systematic is given. Moreover, we present a full validation for MC-ICPMS based $\delta^{11} \mathrm{~B}$ data including an uncertainty calculation for $\delta^{11} \mathrm{~B}$ values of isotope reference materials, plant quality control materials and bell pepper samples.

*Corresponding author: Jochen Vogl, BAM Federal Institute for Materials Research and Testing, Richard-Willstätter-Str.11, 12489 Berlin, Germany, Tel: +49 3081041144; E-mail: jochen.vogl@bam.de

Received August 19, 2015; Accepted September 02, 2015; Published September 07, 2015

Citation: Geilert S, Vogl J, Rosner M, Voerkelius S, Eichert T (2015) Boron Isotope Fractionation in Bell Pepper. Mass Spectrom Purif Tech 1: 101. doi:10.4172/ mso.1000101

Copyright: ( 2015 Geilert S, et al. This is an open-access article distributed under the terms of the Creative Commons Attribution License, which permits unrestricted use, distribution, and reproduction in any medium, provided the original author and source are credited. 


\section{Materials and methods}

\section{Sample materials, standards and reagents}

A bell pepper plant (Capsicum annuum var. annuum) from Gewächshauslaborzentrum Dürnast (GHL), TUM School of Life Sciences Weihenstephan was examined to study intraplant B mass fractions and isotope variations. The bell pepper was grown using a constant nutrient supply throughout the growing period. Bell pepper compartments including roots, stem parts, leaves and fruits (separated into outer and inner pulp as well as seeds) were selected for B analysis. Similar plant parts were sampled at various plant heights in order to assess intraplant B isotope variations. Plant samples were frozen and freeze-dried before decomposition. Certified isotope reference materials from NIST and the European Reference Material (ERM ${ }^{*}$ ) cooperation (NIST SRM 951, ERM-AE120, -AE121, -AE122; Ref. [9] were used as $\delta^{11} \mathrm{~B}=0$ standard and quality control materials, respectively. Plant reference materials (RM) with published $\delta^{11} \mathrm{~B}$ values. [6] like Corn Bran (NIST RM 8433) and Peach Leaves (NIST RM 1547) from NIST, White Cabbage (Bureau Communautaire de Référence, BCR', BCR-679) from the Institute for Reference Materials and Measurements (IRMM) and Maize (International Plant-Analytical Exchange, IPE, IPE 126) from Wageningen Evaluating Programmes for Analytical Laboratories (WEPAL) were used to investigate potential isotope fractionation and contamination during sample preparation and mass spectrometric measurements.

\section{Sample preparation}

Sample decomposition and B-matrix separation of plant compartments were conducted following a modified method described in ref. [6] and ref. [10]. To minimize B contamination sample preparation was carried out in High Efficiency Particulate Arrestance (HEPA)-filtered laminar flow work benches using ultrapure water $\left(\mathrm{H}_{2} \mathrm{O}, 18.2 \mathrm{M} \Omega \cdot \mathrm{cm}\right)$, double-distilled hydrochloric acid $(\mathrm{HCl})$, sodium hydroxide $(\mathrm{NaOH})$ and sodium chloride $(\mathrm{NaCl})$ of highest commercially available purity (99.9999\%). All crucibles and tubes were pre-cleaned with $\mathrm{HCl}$ and $\mathrm{H}_{2} \mathrm{O}$.

Decomposition of plant compartments was achieved by dry ashing using a microwave-assisted ashing system (MILESTONE PYRO). The possibility of B fractionation induced during freeze drying was tested by four differently processed aliquots of a homogeneous bell pepper pulp sample: freshly cut pulp (type 1), frozen pulp (type 2), frozen and freeze-dried pulp (type 3) as well as frozen, freeze-dried and successively ashed pulp (type 4). All test pulp aliquots were digested in a high-pressure asher (HPA) after adding $4 \mathrm{~mL}$ nitric acid $\left(\mathrm{HNO}_{3}\right)$ and $1 \mathrm{~mL}$ hydrogen peroxide $\left(\mathrm{H}_{2} \mathrm{O}_{2}\right)$ and the $\mathrm{B}$ mass fraction was subsequently determined by ICPMS (Thermo Element 2). Resulting B mass fractions, calculated on dry mass basis, of the 4 separately processed fruit pulp samples are $56 \mathrm{mg} / \mathrm{kg}$ (type 1 ), $69 \mathrm{mg} / \mathrm{kg}$ (type 2), $64 \mathrm{mg} / \mathrm{kg}$ (type 3 ) and $70 \mathrm{mg} / \mathrm{kg}$ (type 4) and thus agree well within the expanded uncertainty $(k=2)$ of $9 \mathrm{mg} / \mathrm{kg}$. Based on the presented data, $\mathrm{B}$ isotope fractionation induced by $\mathrm{B}$ loss during freeze-drying seems to be unlikely.

The first of the two B-matrix ion-chromatographic separation steps is cation separation using $0.02 \mathrm{~mol} / \mathrm{L} \mathrm{HCl}$ in columns loaded with 0.5 $\mathrm{mL}$ of the anion exchange resin AG 50W-X8 (see [6] for details). The remaining sample matrix was separated using the boron specific resin Amberlite IRA-743. The resin was cleaned and conditioned in batch mode using $10 \mathrm{ml}$ of resin in total, which was sufficient for 20 samples, each supplied with $\sim 0.5 \mathrm{ml}$ resin. The resin was cleaned with 5 times $1 \mathrm{ml}$ of $6 \mathrm{~mol} / \mathrm{L} \mathrm{HCl}$ and subsequently conditioned using $35 \mathrm{~mL} \mathrm{H}_{2} \mathrm{O}$ and $3 \mathrm{~mL} \mathrm{NaOH}(0.5 \mathrm{~mol} / \mathrm{L})$ in an alternating mode. $\mathrm{NaOH}$ was added in a batch mode and left for about 30 minutes. After conditioning 0.5 $\mathrm{mL}$ of resin were added to the sample solution which was beforehand conditioned to an alkaline media using $2 \mathrm{~mol} / \mathrm{L} \mathrm{NaOH}$. B is thus present in a tetrahedral form $\mathrm{B}(\mathrm{OH})_{4}^{-}$, which binds to the resin while shaking for $24 \mathrm{~h}$. Afterwards, the sample solution and resin were transferred to columns, and the matrix was consecutively washed from the resin using $3 \mathrm{~mL} \mathrm{H}_{2} \mathrm{O}, 1.5 \mathrm{~mL}$ of $0.6 \mathrm{~mol} / \mathrm{L} \mathrm{NaCl}$ and $3 \mathrm{~mL} \mathrm{H} \mathrm{H}_{2} \mathrm{O}$. Finally, $\mathrm{B}$ was eluted using $7 \mathrm{~mL}$ of $0.5 \mathrm{~mol} / \mathrm{L} \mathrm{HCl}$ and was further diluted for $\mathrm{B}$ mass fraction and isotope ratio measurements.

$B$ mass fraction and isotope measurements: $B$ mass fractions were analyzed with a Thermo ${ }^{\circledR}$ Element 2 ICPMS at Bundesanstalt für Materialforschung und -prüfung (BAM) in standard configuration mode using $2 \%(\mathrm{w} / \mathrm{w}) \mathrm{HCl}$. The multi-element standard no. IV from Merck was used for external calibration. Matrix effects were evaluated separately by comparing standard addition and external calibration for digested bell pepper samples. Matrix was found to lead to a signal increase of $8.5 \%$ in average, which results in a correction factor of 0.929 for the external calibration with an expanded uncertainty of 0.085 . The expanded uncertainty of the calibration and sample measurements was estimated to be $10 \%$. When combining both contributions an overall relative expanded uncertainty of $14 \%$ for the mass fraction determination results.

Boron isotope ratios were determined using a Thermo Neptune Plus MC-ICPMS at BAM, where the sample introduction was optimized similar as described in ref. [11]. Boron was analyzed in $2 \%(\mathrm{w} / \mathrm{w}) \mathrm{HCl}$ in low resolution mode, where the ${ }^{10} \mathrm{Ar}^{4+}$ interference is already completely separated. ${ }^{11} \mathrm{~B}$ intensities of about $1.7 \mathrm{~V}$ were achieved for B mass fractions of $200 \mathrm{ng} / \mathrm{g}$, while acid blank values varied between 5 and $10 \mathrm{mV}$, yielding a sample to blank intensity ratio of $>100$. A washout time of $240 \mathrm{~s}$ was sufficient to reduce the B signal to less than $1 \%$ of the signal achieved for $200 \mathrm{ng} / \mathrm{g}$ standards and samples. The samples were measured using the standard bracketing technique. NIST SRM 951 was used as bracketing standard and isotope variations were reported in the $\delta$-notation in per mill following eqn. 1 , where the $R\left({ }^{11} \mathrm{~B} /{ }^{10} \mathrm{~B}\right)_{\text {NIST SRM } 951}$ represents the mean value of the standard before and after the sample.

\section{Method validation and uncertainty budget}

In order to assess the total sample recovery after dry ashing and after B-matrix separation 4 crop plant reference materials (NIST RM 8433 and 1547, BCR-679 and IPE 126) have been processed. The total sample recovery was $\geq 86 \%$, with an average value of $(87 \pm 1) \%$ ( $1 \mathrm{x}$ standard deviation sd). The procedure blank was $\leq 15 \mathrm{ng} \mathrm{B}$, thus sufficiently low considering a sample load of $4 \mu \mathrm{g} B(<0.4 \%)$. To identify any B isotope fractionation induced by sample decomposition and B-matrix separation the certified B isotope reference material ERM-AE120 [9] and the plant quality control materials NIST SRM 8433 and 1547, BCR679 and IPE 126 were processed through the whole procedure. Neither for ERM-AE120 nor for the plant reference materials a difference of the determined $\delta^{11} \mathrm{~B}$ values compared to the certified and published $\delta^{11} \mathrm{~B}$ values outside the expanded uncertainties could be observed (Table 1). The mean offset in $\delta^{11} \mathrm{~B}$ between the determined and the certified and published $\delta^{11} \mathrm{~B}$ values of the five materials of $0.1 \%$ shows the validity of the used procedure (Table 1).

The expanded measurement uncertainty for $\delta^{11} \mathrm{~B}$ determinations by MC-ICPMS in monoelemental solutions was calculated as $0.8 \%$ o based on repeated measurements of the certified $B$ isotope reference materials [9]. 
Citation: Geilert S, Vogl J, Rosner M, Voerkelius S, Eichert T (2015) Boron Isotope Fractionation in Bell Pepper. Mass Spectrom Purif Tech 1: 101. doi:10.4172/mso.1000101

Page 3 of 6

\begin{tabular}{|c|c|c|c|c|c|c|c|}
\hline \multirow[b]{2}{*}{ Material } & \multirow[b]{2}{*}{$\mathrm{n}_{1}{ }^{\mathrm{b}}$} & \multirow[b]{2}{*}{$\mathrm{n}_{2}^{\mathrm{c}}$} & \multicolumn{3}{|c|}{ Measured } & \multicolumn{2}{|c|}{ Reference } \\
\hline & & & $\delta^{11} \mathrm{~B}$ & s.d. & $U(k=2)$ & $\delta^{11} \mathrm{~B}_{(\mathrm{S}) \mathrm{RM}}$ & $U(k=2)$ \\
\hline & & & $(\%)$ & $(\%)$ & $(\%)$ & $(\%)$ & $(\%)$ \\
\hline$E R M \circledR-A E 120$ & 1 & 22 & -20.3 & 0.4 & 0.8 & -20.2 & 0.6 \\
\hline $\mathrm{ERM} \otimes-\mathrm{AE} 120^{\mathrm{a}}$ & 3 & 9 & -19.5 & 0.2 & 0.8 & -20.2 & 0.6 \\
\hline ERM® - AE 121 & 1 & 35 & 19.5 & 0.3 & 0.8 & 19.9 & 0.6 \\
\hline ERM® - AE 122 & 1 & 29 & 39.5 & 0.3 & 0.8 & 39.7 & 0.6 \\
\hline BCR-679 Cabbage & 4 & 28 & -23.6 & 0.7 & 1.3 & -23.8 & 1.2 \\
\hline NIST Peach leaves (RM 1547) & 2 & 11 & 40.5 & 0.3 & 1.2 & 41.1 & 1.1 \\
\hline NIST Corn Bran (RM 8433) & 2 & 11 & 7.9 & 0.7 & 1.3 & 8.3 & 1.7 \\
\hline IPE Maize (WEPAL IPE126) & 2 & 7 & 1.0 & 0.2 & 1.2 & 0.4 & 1.2 \\
\hline $\begin{array}{l}\text { aChemically processed } \\
\text { bNumber of aliquots } \\
\text { 'Number of measurements }\end{array}$ & & & & & & & \\
\hline
\end{tabular}

Table 1: $\delta^{11} \mathrm{~B}$ values with their expanded uncertainties as determined for certified reference materials (ERM $\left.{ }^{\circledR}-A E 120,-A E 121,-A E 122\right)$ and plant reference materials (White Cabbage BCR-679, Peach Leaves NIST SRM 1547, Corn Bran NIST RM 8433 and Maize WEPAL IPE 126) are shown. Calculation of the expanded uncertainties is explained in the text and performed after a method by ref. [6] The certified reference material ERM ${ }^{\circledR}-A E 120^{a}$ is processed through the matrix separation procedure to test for fractionation effects or B loss (see text for details).

ERM-AE120 $\left(\mathrm{n}=22\right.$; average $\left.\delta^{11} \mathrm{~B}=-20.3 \pm 0.8 \%\right)$, ERM-AE121 $\left(\mathrm{n}=35\right.$; average $\delta^{11} \mathrm{~B}=-19.6 \pm 0.8 \%$ ) and ERM-AE122 $(\mathrm{n}=29$; average $\left.\delta^{11} \mathrm{~B}=39.6 \pm 0.8 \% 0\right)$. $\delta^{11} \mathrm{~B}$ values obtained on plant reference materials agree well within the stated uncertainties (1.2\%o to $1.3 \%$ ) with previously measured $\delta^{11} \mathrm{~B}$ values by ref. [6] (Table 1).

The calculated uncertainty budget for the plant reference materials and for the bell pepper samples is based on ref. [12] and contains uncertainty contributions from sample decomposition $\left(\kappa_{1}=0.41 \%\right)$, B-matrix separation $\left(\kappa_{2}=0.25 \%\right)$, procedure blank $\left(\kappa_{3}=0.16 \%\right.$ ), isotopic heterogeneity of the reference material NIST SRM $951\left(\kappa_{4}=0.2 \% 0\right)$. For MC-ICPMS measurements it is expanded by fluctuation or drift of the instrumental mass bias $\left(\kappa_{5}=0.2 \% 0\right)$ and matrix effects on the instrumental mass discrimination $\left(\kappa_{6}=0.2 \% 0\right)$. Uncertainty contributions of the determined sample and bracketing standard isotope ratios $\left(R_{\text {sample }}\right.$ and $\left.R_{\text {NIST SRM } 951}\right)$ are treated after equation 2:

$$
\delta^{11} \mathrm{~B}=\left(\frac{\left(R_{\text {sample }} \cdot \kappa_{1} \cdot \kappa_{2} \cdot \kappa_{3}\right)}{\left(R_{\text {NIST SRM } 951} \cdot \kappa_{4}\right)} \cdot \kappa_{5} \cdot \kappa_{6}\right)-1
$$

The expanded uncertainties for the bell pepper samples range between $1.3 \%$ and $1.9 \%$ with an average value of $1.5 \%$ (Table 2 ). The uncertainty budget is mainly influenced by contributions derived from the sample preparation prior the MC-ICPMS. The sample decomposition $\left(\kappa_{1}\right)$, B-matrix separation $\left(\kappa_{2}\right)$ and the procedure blank $\left(\kappa_{3}\right)$ typically account for about two thirds of the uncertainty and the MC-ICPMS related contributions $\left(\kappa_{5}, \kappa_{6}, R_{\text {sample }}\right.$ and $\left.R_{\text {NIST SRM 951 }}\right)$ are responsible for only one third of the uncertainty. The expanded uncertainties of $\leq 1.9 \%$ calculated in this study represent the limit of interpretation of the bell pepper $\delta^{11} \mathrm{~B}$ values determined here. This limit is completely sufficient as the $\delta^{11} \mathrm{~B}$ values observed in this study range from $-11.0 \%$ to $+16.0 \%$ o (Table 2 ).

\section{Results and Discussion}

\section{Boron mass fraction and isotope composition of plant compartments}

The B mass fraction (dry weight) varied significantly between different plant compartments, but was consistent within the same compartment type (Table 2) (Figure 1a). Roots showed a B mass fraction of $16 \mathrm{mg} / \mathrm{kg}$. Stem 1 ( $8 \mathrm{~cm}$ above soil), stem 2 (92 cm above soil) and stem 3 (147 cm above soil) had B mass fractions of $14 \mathrm{mg} / \mathrm{kg}$, $15 \mathrm{mg} / \mathrm{kg}$ and $14 \mathrm{mg} / \mathrm{kg}$, respectively. Leaf 1 (108 cm above soil), leaf 2 (125 cm above soil) and leaf $3(147 \mathrm{~cm}$ above soil) showed B mass fractions of $65 \mathrm{mg} / \mathrm{kg}, 49 \mathrm{mg} / \mathrm{kg}$ and $60 \mathrm{mg} / \mathrm{kg}$, respectively. Bell pepper fruit 1 (108 cm above soil) consisted of yellow pulp and had a B mass fraction of $9 \mathrm{mg} / \mathrm{kg}$. The white inner pulp showed a B mass fraction of $22 \mathrm{mg} / \mathrm{kg}$ and the seeds $28 \mathrm{mg} / \mathrm{kg}$. The green bell pepper fruit $2(125 \mathrm{~cm}$ above soil) showed a B mass fraction of $12 \mathrm{mg} / \mathrm{kg}$, corresponding white pulp $19 \mathrm{mg} / \mathrm{kg}$ and seeds $20 \mathrm{mg} / \mathrm{kg}$. The fruit stem of the green bell pepper had a B mass fraction of $17 \mathrm{mg} / \mathrm{kg}$ and was thus just minimally lower than the white pulp and seeds. Highest B mass fractions were found in the leaves and lowest in the green and yellow bell pepper pulp.

In contrast to the $\mathrm{B}$ mass fraction, $\delta^{11} \mathrm{~B}$ values showed a distinct variation dominated by an increase the higher the plant compartments were located in the plant, or the greater the distances were to the roots (Table 2) (Figure $1 \mathrm{~b}$ ). The $\delta^{11} \mathrm{~B}$ value of the roots was $-11.0 \pm 1.3 \%$. Stem 1 showed a $\delta^{11} \mathrm{~B}$ value of $-(10.2 \pm 1.3) \%$ and equals thereby the $\delta^{11} \mathrm{~B}$ values of the roots. Stem 2 and 3 had $\delta^{11} \mathrm{~B}$ values of $-(5.8 \pm 1.4) \%$ and $-(2.1 \pm 1.9) \%$, respectively. Thus, an increase of about $\Delta^{11} \mathrm{~B}_{\text {sten }}$ ${ }_{\text {stem } 1}=8.1 \%$ over a distance of $139 \mathrm{~cm}$ was observed, with $\Delta^{11} \mathrm{~B}_{\text {stem3-stem } 1}$ being defined by eqn. 3 . The leaves showed a similar increase from $\delta^{11} \mathrm{~B}=+(9.0 \pm 1.5) \%$ o (leaf 1$)$ to $+(16.0 \pm 1.6) \%$ o (leaf 2$)$ and $+(15.7 \pm$ $1.3) \%$ (leaf 3 ) over a distance of $39 \mathrm{~cm}$ resulting in a $\Delta^{11} \mathrm{~B}_{\text {leaf3-leafl }}=6.7 \%$.

$$
\Delta^{11} \mathrm{~B}_{\mathrm{x}-\mathrm{y}}=\delta^{11} \mathrm{~B}(\mathrm{x})-\delta^{11} \mathrm{~B}(\mathrm{y})
$$

With $\mathrm{x}$ equal to higher located pant parts (e.g. stem 3, leaf 3 ) and $\mathrm{y}$ equal to lower located plant parts (e.g. stem 1, leaf 1).

The outer yellow and green pulp of the bell pepper fruits 1 and 2 equaled each other in their $\delta^{11} \mathrm{~B}$ signature with values of $+(11.7 \pm 1.5) \%$ and $+(11.9 \pm 1.4) \%$, respectively. The $\delta^{11} \mathrm{~B}$ values of the here investigated bell pepper outer pulp samples fell in the range of -7 to $+37 \%$ determined for European and Mediterranean bell pepper fruits [7]. The white pulp with $\delta^{11} \mathrm{~B}$ values of $+(6.5 \pm 1.5) \%$ (fruit 1 ) and $+(6.1 \pm 1.3) \%$ (fruit 2$)$ compared well with each other. Seeds with $\delta^{11} \mathrm{~B}$ of $+(4.3 \pm 1.3) \%$ (fruit 1$)$ and $\delta^{11} \mathrm{~B}$ of $+(6.4 \pm 1.3) \%$ (fruit 2) also equaled each other within uncertainty. The fruit stem of fruit 2 was with $\delta^{11} \mathrm{~B}$ of $+(5.5 \pm 1.8) \%$ similar to the white pulp and seeds. In summary, an increase in $\delta^{11} \mathrm{~B}$ from $-11.0 \%$ (roots) to $+16.0 \%$ (leaf 2 ) could be observed (Figures 1 and 2). A fractionation of about $\Delta^{11} \mathrm{~B}_{\text {leaf }}$ $=27 \%$ within a single plant was thus present (Table 2) (Figures 1 and 2). In general, no correlation between $B$ mass fraction and boron isotope distribution could be observed (Figure 2). Just the leaves showed the highest $B$ mass fractions (on average $58 \mathrm{mg} / \mathrm{kg}$ ) which coincided also with the highest $\delta^{11} \mathrm{~B}$ values (on average $+13.6 \%$ ). The outer pulp of the bell pepper fruits showed lowest $\mathrm{B}$ mass fractions and 
highest $\delta^{11} \mathrm{~B}$ values compared to the inner fruit parts (inner pulp, seeds and fruit stem). Despite different growth heights of the bell pepper fruits (108 cm yellow fruit, $125 \mathrm{~cm}$ green fruit) their $\delta^{11} \mathrm{~B}$ values, were equal within uncertainty. This contrasted to the $\delta^{11} \mathrm{~B}$ values of stems and leaves, which showed a distinct dependency on the growth height (Table 2) (Figure 1). This difference between fruits and other plant compartments could indicate a certain threshold in the fruits regulating $\mathrm{B}$ uptake and $\mathrm{B}$ isotope fractionation. Additionally, a fractionation of about $\Delta^{11} \mathrm{~B}_{\text {OuterPulp-InnerParts }}=7 \%$ was observed between fruit outer pulp and inner white pulp, seeds and fruit stem. A negative correlation between $\delta^{11} \mathrm{~B}$ values and $\mathrm{B}$ mass fractions was found in which the outer bell pepper pulp showed the lowest B mass fraction and the highest $\delta^{11} \mathrm{~B}$ values (Figure 2).

\section{Intra-plant B isotope fractionation}

The continuous increase in $\delta^{11} \mathrm{~B}$ from the roots to the top of the bell pepper can be the result of different isotope fractionation steps during $\mathrm{B}$ transport and incorporation into the plant cells. Boron loss via transpiration is unlikely. Among various possible B fractionation scenarios the preferential incorporation of the light ${ }^{10} \mathrm{~B}$ isotope into the cell or integration into the cell walls leading to an upward transportation of boron being enriched in the heavy ${ }^{11} \mathrm{~B}$ isotope is discussed in the following.

B uptake and transport through plant-membranes is channelmediated via aquaporines, which direct boric acid into the xylem [13]. Due to thermodynamic reasons boric acid preferentially incorporates the heavy isotope in contrast to borate. Therefore, a preferred transport of ${ }^{11} \mathrm{~B}$ into the xylem and via transporters to higher located plant parts can be assumed. B transporters were found not only to facilitate B uptake into the xylem but also to regulate $B$ uptake and transport in the shoots. The efflux B transporter (BOR1, borate exporter) and the nodulin 26-like intrinsic protein 6;1 (NIP6;1, boric acid transporter) were held responsible for a preferential B transport to growing young leaves and shoot compartments through carrier- or channelmediated transport $[14,15]$. Nevertheless, the molecular mechanisms and dominance of these transporters and channels are not yet fully understood [15]. In ref. [15], it was found that the transporter NIP6;1 facilitates the transport of boric acid through the xylem to newly growing plant compartments and thus agrees well with a preferential transport of ${ }^{11} \mathrm{~B}$ towards the top of the plant as observed in the studied bell pepper plant.

The preferred transport of boric acid to younger plant parts at the top of the plant might additionally be verified by the B mass fractions. For this consideration, however, it has to be differentiated between the classes of plant parts. The leaves for instance show similar B mass fractions independent of height and therefore age. Typically $B$ in plants is enriched in older plant parts compared to younger plant parts; with growing time $\mathrm{B}$ also gets accumulated in the younger plant parts and $\mathrm{B}$ mass fractions increase. However, given that in rapidly growing plants $\mathrm{B}$ is preferentially transported to young, newly growing plant parts no discrepancies exist between $B$ mass fractions in old and young plant parts. Given that in the studied bell pepper, B mass fractions equal each other for instance in the leaves (Table 2), a rapid growth can be assumed and a preferred transport of boric acid and thereby the heavy ${ }^{11} \mathrm{~B}$ isotope to younger plant parts can be explained.

The presented $\mathrm{B}$ isotope data do not exclude an additional fractionation during $\mathrm{B}$ incorporation into plant cells. The systematic increase in $\delta^{11} \mathrm{~B}$ from roots to leaves implies that fractionation related to $\mathrm{B}$ transport is the dominant fractionation mechanism. However, a constant fractionation between xylem sap and cells is likely as B undergoes a speciation change (from trigonal coordinated boric acid to tetrahedral borate) during fixation in the cells [2]. Given that cell-fixed borate preferentially incorporates the light $\mathrm{B}$ isotope the remaining xylem sap will get enriched in ${ }^{11} \mathrm{~B}(\mathrm{OH})_{3}$ and ${ }^{11} \mathrm{~B}$ will consequently be transported to higher located plant parts. This might be an additional process which might explain the lighter $\delta^{11} \mathrm{~B}$ values in the lower and the heavier values in the upper plant parts (Figures 1 and 2). This goes along with the age of the plant parts. Older plant parts show lower $\delta^{11} \mathrm{~B}$ values than younger plant parts, because more time was available for this fractionation process and the boron delivered to the younger plant parts is already depleted in ${ }^{10} \mathrm{~B}$ : stem 1 to stem 2 to stem 3 show increasing $\delta^{11} \mathrm{~B}$ values (Figure 1), with increasing height and decreasing age; slightly less pronounced this effect is visible for leave 1 compared to leave 2 and 3 (Figure 1).

Further, the highest $\delta^{11} \mathrm{~B}$ enrichment is not exclusively found in the uppermost plant parts (e.g., leaves 2 compared to fruit 2). This observation implies that not the growth height alone is responsible for the observed $\delta^{11} \mathrm{~B}$ values but that the length of the transport way could be an additional crucial factor. Certainly, plant parts located higher in the plant have a longer transport way than plant parts in lower plant sections, but horizontally stretching stems add essentially to the total transport way. However, this hypothesis needs further investigation to verify the importance of the transport way.

The lower $\mathrm{B}$ concentrations and $\delta^{11} \mathrm{~B}$ values in the fruits compared to the leaves can further be explained by the fact that nutrient supply in the fruits is mostly conducted via the phloem. Therefore, unlike $\mathrm{B}$ in leaves, B in fruits was not directly imported from roots via the xylem but from other organs like leaves. In low-polyol plants, like bell peppers, phloem mobility of $B$ is very low [16] and this might explain the lower B concentration in the fruits. A preferred relocation of one isotope over the other cannot unequivocally be determined as fruit 1 is slightly heavier $(+2.7 \%$ o $)$ than the leaf at the same height and fruit two is slightly lighter compared to the corresponding leaf $(-4.1 \%$ ) (Table 2).

\section{Conclusions}

The $\delta^{11} \mathrm{~B}$ values of different compartments of a bell pepper plant were determined using a fully validated procedure and a systematic increase in $\delta^{11} \mathrm{~B}$ from roots to leaves with a fractionation of $\Delta^{11} \mathrm{~B}_{\text {leat }}$ $=27 \%$ o was identified. A process which preferentially transports ${ }^{11} \mathrm{~B}$ in the form of the boric acid molecule upwards to newly growing plant parts is able to explain the observed systematic B isotope variability. Certain transporters can be held responsible for a discrimination between the transported B species (boric acid versus borate), which might explain the $\mathrm{B}$ isotope systematic.

Given the here determined large intra-plant B isotope variability the use of $B$ isotopes for plant/food provenance studies may be limited as geographical differences in $\mathrm{B}$ isotope signatures are additionally controlled by plant internal fractionation processes. However, as long as whole plants or same plant compartments were compared B isotopes might be used to identify natural reservoirs or anthropogenic processes (like fertilization).

Nevertheless, the large $\Delta^{11} \mathrm{~B}$ fractionation observed here in a single bell pepper plant can help to improve the knowledge about plant metabolism. B isotopes could be used as tracers to study B transport and speciation.

Open questions remain concerning plant internal $\mathrm{B}$ isotope fractionation. It needs to be clarified if the shift of $\Delta^{11} B_{\text {leaf-rots }}=27 \%$ in full grown bell pepper plants is constant or if it varies depending on external conditions like irrigation water, B uptake time or transport 
Citation: Geilert S, Vogl J, Rosner M, Voerkelius S, Eichert T (2015) Boron Isotope Fractionation in Bell Pepper. Mass Spectrom Purif Tech 1: 101. doi:10.4172/mso.1000101

Page 5 of 6

\begin{tabular}{|c|c|c|c|c|c|c|c|c|}
\hline Sample & Height above soil & Aliquot No. & B mass fraction ${ }^{a}$ & $\delta^{11} \mathrm{~B}$ & s.d. ${ }^{b}$ & Average $\delta^{11} \mathrm{~B}$ & s.d. ${ }^{c}$ & $U(k=2)$ \\
\hline & $(\mathrm{cm})$ & & $(\mathrm{mg} / \mathrm{kg})$ & $(\%)$ & $(\%)$ & $(\%)$ & $(\%)$ & $(\%)$ \\
\hline \multirow[t]{2}{*}{ Roots } & I & 1 & $16(2)$ & -10.7 & 0.8 & \multirow{2}{*}{-11.0} & \multirow{2}{*}{0.7} & \multirow{2}{*}{1.3} \\
\hline & & 2 & & -11.3 & 0.5 & & & \\
\hline \multirow[t]{2}{*}{ Stem 1} & 8 & 1 & $14(2)$ & -10.5 & 0.7 & \multirow{2}{*}{-10.2} & \multirow{2}{*}{0.7} & \multirow{2}{*}{1.3} \\
\hline & & 2 & & -9.7 & 0.5 & & & \\
\hline \multirow[t]{2}{*}{ Stem 2} & 92 & 1 & $15(2)$ & -5.4 & 0.3 & \multirow{2}{*}{-5.8} & \multirow{2}{*}{0.6} & \multirow{2}{*}{1.4} \\
\hline & & 2 & & -6.1 & 0.7 & & & \\
\hline \multirow[t]{2}{*}{ Stem 3} & 147 & 1 & $14(2)$ & -0.1 & 0.6 & \multirow{2}{*}{-2.1} & \multirow{2}{*}{1.9} & \multirow{2}{*}{1.9} \\
\hline & & 2 & & -3.6 & 0.3 & & & \\
\hline \multirow[t]{2}{*}{ Bell pepper fruit 1 Pulp (yellow) } & 108 & 1 & $9(1)$ & 10.8 & 0.5 & \multirow{2}{*}{11.7} & \multirow{2}{*}{1.1} & \multirow{2}{*}{1.5} \\
\hline & & 2 & & 12.7 & 0.3 & & & \\
\hline \multirow[t]{2}{*}{ Bell pepper fruit 1 Pulp (white) } & 108 & 1 & $22(3)$ & 5.6 & 0.5 & \multirow{2}{*}{6.5} & \multirow{2}{*}{1.1} & \multirow{2}{*}{1.5} \\
\hline & & 2 & & 7.5 & 0.3 & & & \\
\hline \multirow[t]{2}{*}{ Bell pepper fruit 1 seeds } & 108 & 1 & $28(4)$ & 4.0 & 0.6 & \multirow{2}{*}{4.3} & \multirow{2}{*}{0.6} & \multirow{2}{*}{1.3} \\
\hline & & 2 & & 4.7 & 0.3 & & & \\
\hline \multirow[t]{2}{*}{ Bell pepper fruit 2 Pulp (green) } & 125 & 1 & $12(2)$ & 11.4 & 1.0 & 110 & 09 & 14 \\
\hline & & 2 & & 12.5 & 0.3 & 11.9 & 0.9 & 1.4 \\
\hline Bell pepper fruit 2 Pulp (white) & 125 & 1 & $19(3)$ & 6.3 & 0.4 & 61 & 04 & 13 \\
\hline & & 2 & & 5.9 & 0.4 & 0.1 & 0.4 & 1.0 \\
\hline Bell pepper fruit 2 seeds & 125 & 1 & $20(3)$ & 5.6 & 0.6 & 64 & 05 & 13 \\
\hline & & 2 & & 6.7 & 0.2 & 0.4 & 0.5 & 1.3 \\
\hline Fruit stem & 125 & 1 & $17(2)$ & 6.9 & 0.9 & 5 & 10 & 10 \\
\hline & & 2 & & 4.1 & 0.1 & 0.0 & 1.0 & 1.8 \\
\hline Leaf 1 & 108 & 1 & $65(9)$ & 8.0 & 0.3 & 90 & 11 & 15 \\
\hline & & 2 & & 10.0 & 0.3 & 9.0 & 1.1 & 1.0 \\
\hline Leaf 2 & 125 & 1 & $49(7)$ & 15.1 & 0.8 & 160 & 12 & 16 \\
\hline & & 2 & & 17.0 & 0.6 & 16.0 & 1.2 & 1.0 \\
\hline Leaf 3 & 147 & 1 & $60(8)$ & 15.5 & 0.4 & 157 & 04 & 12 \\
\hline & & 2 & & 16.0 & 0.3 & 10.1 & 0.4 & 1.0 \\
\hline $\begin{array}{l}\text { aExpanded measurement uncert } \\
\text { 'S Standard deviation of replicate } \\
\text { 'Standard deviation of all measu }\end{array}$ & $\begin{array}{l}(\mathrm{k}=2) \text { given in brac } \\
\text { urements } \\
\text { tts }(n=5-7)\end{array}$ & rets and appl & & & & & & \\
\hline
\end{tabular}

Table 2: B mass fraction and $\delta^{11} \mathrm{~B}$ values of the bell pepper plant. Standard deviation of the measurements and expanded uncertainties are reported. The uncertainty for the $\delta^{11} \mathrm{~B}$ values was calculated after ref. [6], see text for explanation. All aliquots were measured 3 times, beside aliquot 1 of sample stem 1 and aliquot 2 of sample stem 3 , which were measured 4 times and aliquot 1 of sample leaf 1 which was measured 2 times.
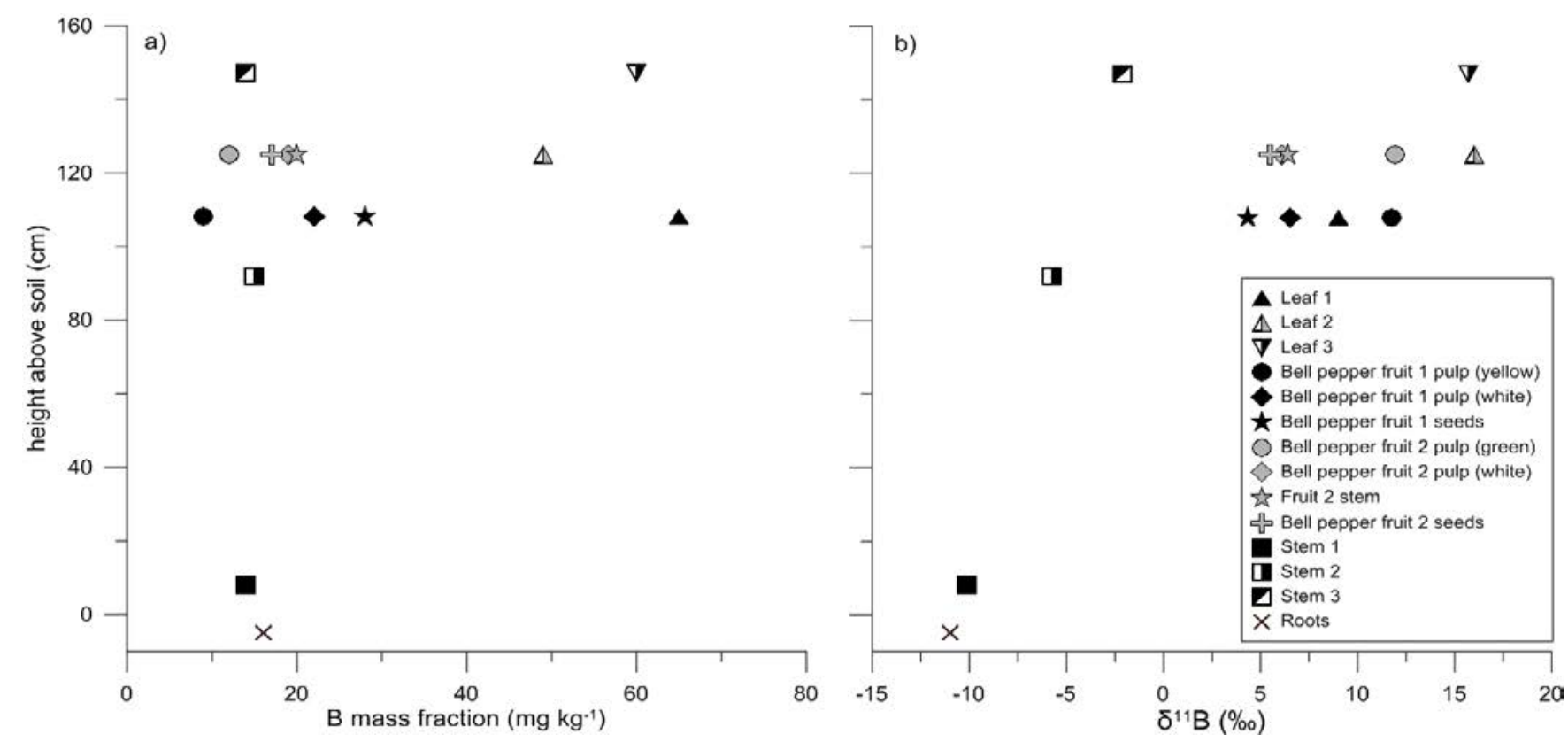

Figure 1: Intraplant B mass fractions (a) and $\delta^{11} \mathrm{~B}$ values (b) plotted against the growth height (cm). 
Citation: Geilert S, Vogl J, Rosner M, Voerkelius S, Eichert T (2015) Boron Isotope Fractionation in Bell Pepper. Mass Spectrom Purif Tech 1: 101. doi:10.4172/mso.1000101

Page 6 of 6

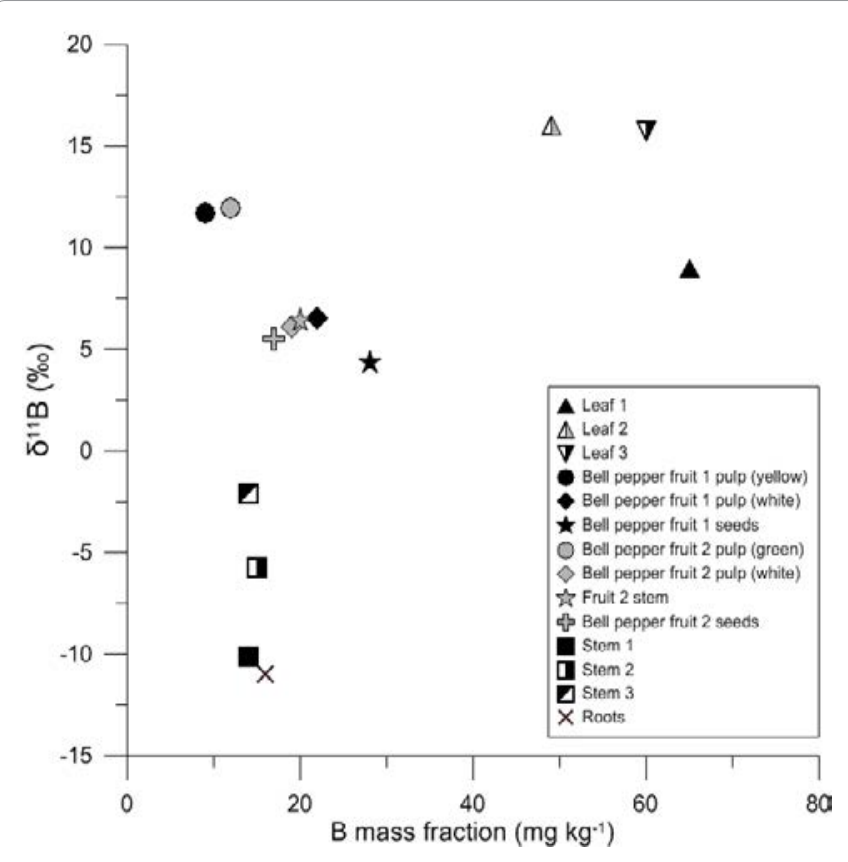

Figure 2: Bell pepper $\delta^{11} \mathrm{~B}$ values $(\%)$ plotted against the corresponding $\mathrm{B}$ mass fraction. A correlation between $B$ isotope values and mass fraction cannot be obtained. The only positive trend is existent in the leaves, which show the highest $B$ mass fraction as well as the highest $\delta^{11} B$ values.

way. Further, it needs to be understood how B isotopes are fractionated during B uptake when high or low B supply occurs.

\section{Acknowledgments}

We would like to thank the Gewächshauslaborzentrum Dürnast (GHL), TUM School of Life Sciences Weihenstephan for the supply of the bell pepper plant. Further the support for sample digestion and chemical procedures by Dorit Becker is greatly appreciated. We would also like to thank Maren Koenig for the assistance with the $\mathrm{B}$ mass fraction measurements.

\section{References}

1. Kelly S, Heaton K, Hoogewerff J (2005) Tracing the geographical origin of food: The application of multi-element and multi-isotope analysis. Trends in Food Science \& Technology 16: 555-567.
2. O'Neill MA, Ishii T, Albersheim P, Darvill AG (2004) Rhamnogalacturonan II: structure and function of a borate cross-linked cell wall pectic polysaccharide. Annu Rev Plant Biol 55: 109-139.

3. Vengosh A, Kolodny Y, Starinsky A, Chivas A R, McCulloch M T (1991) Coprecipitation and isotopic fractionation of boron in modern biogenic carbonates. Geochimica et Cosmochimica Acta 55: 2901-2910.

4. Vanderpool R A, Johnson P E (1992) Boron Isotope Ratios in Commercial Produce and Boron-10 Foliar and Hydroponic Enriched Plants. Journal of Agriculture and Food Chemistry 40: 462-466.

5. Wieser M E, lyer S S, Krouse H R, Cantagallo M I (2001) Variations in the boron isotope composition of Coffea arabica beans. Applied Geochemistry 16: 317-322.

6. Rosner M, Pritzkow W, Vogl J, Voerkelius S (2011) Development and validation of a method to determine the boron isotopic composition of crop plants. Anal Chem 83: 2562-2568.

7. Rosner M, Vogl J (2012) Bor: Isotopenverhältnisse und die Herkunft einer Probe. Nachrichten aus der Chemie 60: 147-149.

8. Marentes E, Vanderpool R A, Shelp B J (1997) Boron-isotope fractionation in plants. Canadian Journal of Plant Science 77: 627-629.

9. Vogl J, Rosner M (2011) Production and Certification of a Unique Set of Isotope and Delta Reference Materials for Boron Isotope Determination in Geochemical, Environmental and Industrial Materials. Geostandards and Geoanalytical Research 36: 161 -175.

10. Lemarchand D, Gaillardet J, Göpel C, Manhès, G (2002) An optimized procedure for boron separation and mass spectrometry analysis for river samples. Chemical Geology 182: 323-334.

11. Vogl J, Rosner M, Pritzkow W (2011) Development and validation of a single collector SF-ICPMS procedure for the determination of boron isotope ratios in water and food samples. Journal of Analytical Atomic Spectrometry 26: 861-869.

12. Rosner M, Vogl J (2013) Approaching Real Uncertainty Estimates for d11B Data. Mineralogical Magazine 77: 2085.

13. Dordas C, Brown P H (2001) Evidence for channel mediated transport of boric acid in squash (Cucurbita pepo). Plant Soil 235: 95-103.

14. Takano J, Yamagami M, Noguchi K, Hayashi H, Fujiwara T (2001) Preferential Translocation of Boron to Young Leaves in Arabidopsis thaliana Regulated by the BORI Gene. Soil Science and Plant Nutrition 47: 345-357.

15. Tanaka M, Wallace IS, Takano J, Roberts DM, Fujiwara T (2008) NIP6;1 is boric acid channel for preferential transport of boron to growing shoot tissues in Arabidopsis. Plant Cell 20: 2860-2875.

16. Brown $\mathrm{P} \mathrm{H}, \mathrm{Hu} \mathrm{H}$ (1998) Phloem boron mobility in diverse plant species. Bot Acta 111: 331-335.
Citation: Geilert S, Vogl J, Rosner M, Voerkelius S, Eichert T (2015) Boron Isotope Fractionation in Bell Pepper. Mass Spectrom Purif Tech 1: 101. doi:10.4172/mso.1000101
OMICS International: Publication Benefits \& Features Unique features:

- Increased global visibility of articles through worldwide distribution and indexing Showcasing recent research output in a timely and updated manner

- Special issues on the current trends of scientific research

Special features:

- 700 Open Access Journals

50,000 editorial team

process

Quality and quick editorial, review and publication processing

Indexing at PubMed (partial), Scopus, EBSCO, Index Copernicus, Google Scholar etc.

Sharing Option: Social Networking Enabled

Authors, Reviewers and Editors rewarded with online Scientific Credits

Better discount for your subsequent articles

Submit your manuscript at: http://www.omicsonline.org/submission 